Biking Where Black: Connecting Transportation Planning and Infrastructure to Disproportionate Policing

Jesus M. Barajas

Department of Environmental Science and Policy

University of California, Davis

1 Shields Ave.

Davis, CA 95616

ORCID: 0000-0001-8966-5778

Author's Note: This is a pre-print of an article accepted for publication in Transportation Research Part D: Transport and Environment. 


\title{
Biking Where Black: Connecting Transportation Planning and Infrastructure to Disproportionate Policing
}

\author{
Jesus M. Barajas
}

August 9, 2021

This study asks whether deficiencies in transportation are associated with disproportionate policing in Chicago using the case of cycling. I examine how the number of bicycle citations issued per street segment are influenced by the availability of bicycle facilities and street characteristics, controlling for crash incidence, police presence, and neighborhood characteristics. Tickets were issued 8 times more often per capita in majority Black tracts and 3 times more often in majority Latino tracts compared to majority white tracts. More tickets were issued on major streets, but up to $85 \%$ fewer were issued when those streets had bike facilities, which were less prevalent in Black and Latino neighborhoods. Tickets were not associated with bicycle injury-crashes and inversely associated with vehicle injury-crashes. Infrastructure inequities compound the effects of racially-biased policing in the context of transportation safety strategies. Remedies include the removal of traffic enforcement from safe systems strategies and equitable investment in cycling.

Keywords: cycling, policing, mobility justice, infrastructure, safety

\section{Introduction}

In 2010, 623 cyclists died in traffic crashes in the United States, the lowest total since 1994. But fatalities have steadily climbed since then. Just eight years later, the most recent year for which data are available, 857 cyclists lost their lives in traffic crashes - a 38\% increase and the highest reported number in over two decades (National Highway Traffic Safety Administration, 2019). Pedestrian fatalities have reached record highs, too. Researchers and safety advocates have called for an overhaul of the traditional 3 Es approach to safety focused on engineering, education, and enforcement to one that mitigates the impacts of crashes through a safe systems approach (Dumbaugh et al., 2020). This approach, which places much more emphasis on using data to target and design the most effective roadway countermeasures that would eliminate traffic fatalities, has been adopted in the United States as Vision Zero (Fleisher et al., 2016). 
The data-driven approach to crash reduction has revealed stark disparities in who is most vulnerable and where. In San Francisco, for example, 31\% of city streets are located in communities of concern — that is, neighborhoods with high concentrations of low-income residents, immigrants, and seniors - but $50 \%$ of the streets with the highest number of traffic injuries are located in those same communities (Vision Zero SF, 2019). Similar patterns are evident in other large cities, such as Los Angeles and Chicago (City of Chicago, 2017; City of Los Angeles, 2015). And the patterns in national, individual-level statistics are no different. Between 2016 and 2018, 15\% of all bicycle fatalities involved Black cyclists, but Black people made up only $12 \%$ of the population, accounted for $6 \%$ of all bicycle trips, and contributed to only $4 \%$ of total bicycle miles traveled. Latino cyclists comprised $16 \%$ of all fatalities while making up $18 \%$ of the population, but made only $12 \%$ of cycling trips and contributed $13 \%$ of cycling miles. White cyclists were overrepresented in fatalities relative to the share of the white population, but underrepresented relative to trips taken and miles traveled (Federal Highway Administration, 2017; National Highway Traffic Safety Administration, 2019; U. S. Census Bureau, 2020).

Understanding the distribution of vulnerability and harm calls attention to equity and justice issues in safe systems approaches like Vision Zero. Communities of concern—including Black, Latino, and low-income neighborhoods - tend to be the most dangerous places for cyclists and other road users, a result in part from historic disinvestment and failure to provide adequate infrastructure. And though not the emphasis as in traditional safety strategies, safe systems approaches still call for an element of traffic enforcement to combat the most dangerous driving behaviors. When police are deployed to neighborhoods with this objective, it raises the 
likelihood that stops unrelated to direct safety needs would proliferate. For this reason, advocates and scholars alike have questioned the need for policing as part of a holistic safety strategy in approaches like Vision Zero because of the disproportionate effects of policing on communities of color, and have called for alternative methods of engagement that do not involve armed law enforcement (Conner, 2017; Shahum, 2020; Untokening Collective, 2017). Indeed, some cities, including Berkeley, Calif., have adopted policies to remove armed police from traffic calls. But strong racial justice advocates must be engaged to push these kinds of policies forward to planners and city officials focused broadly on Vision Zero outcomes (Abonour, 2018). Planners must grapple with the unintended consequences of safety efforts; while there is plenty of evidence through lived experience that shows how policing has been harmful to Black and Brown communities, there is little research to quantify the extent to which transportation infrastructure can correct that damage.

Using bicycling in the city of Chicago as a case, I describe the extent of racial disparities in citations issued for riding a bicycle on the sidewalk and ask whether street infrastructure mitigates those disparities. Drawing on the literature about cyclists' preferences for dedicated bicycle facilities, I hypothesize that the provision of facilities on higher-traffic streets will be associated with fewer citations because cyclists will feel more comfortable riding in the street rather than on a sidewalk, and I expect that these patterns will hold to a greater degree for separated bicycle infrastructure. However, given extensive documentation of racial bias in policing, I hypothesize that infrastructure is not enough to counteract racial bias in policing, and I expect that disparities will remain after accounting for infrastructure. The results bear these hypotheses out: I find that while evidence exists for persistent bias in the distribution of bicycle 
citations in Black and Latino neighborhoods, inequities in cycling infrastructure are also associated with excess tickets in communities of color, representing compounding inequities. While this is not evidence of a biking while Black effect, it does suggest a relationship to biking where Black, in which neighborhood conditions, including sociodemographic characteristics, are associated with excess policing. I proceed next by reviewing the evidence detailing the incidence and effects of racially-biased policing in traffic stops, as well as the literature that shows how bicycle infrastructure affects behavior and safety outcomes.

\section{Literature Review}

\subsection{Policing mobility}

Recent events in the United States have drawn global attention to the violence that Black communities face at the hands of the police (Taylor, 2020). Traffic stops are the most common form of interaction between the police and the public, and a wealth of evidence points to persistent disparities in stops, tickets, and arrests for Black people compared to other groups. One study that examined data from 20 million vehicle traffic stops over 18 years in North Carolina found evidence for pervasive racial bias across police departments of all sizes, many times because traffic stops were used as a strategy of targeting communities of color for additional policing (Baumgartner et al., 2018). In another North Carolina study, researchers interviewed 2,920 drivers and found that young Black men were stopped twice as often as white men (Warren et al., 2006). In a wide-ranging study that examined data from 100 million traffic stops across 50 municipal and state police departments, researchers found that Black drivers are stopped roughly $40 \%$ more often per capita than white drivers (Pierson et al., 2020). By adjusting for time of day, they found that Black drivers make up a smaller share of the total number of 
drivers stopped at night. In other words, when police could not readily tell the race of the driver because it was dark, Black people were stopped no more often than white people. Stop rates are not static, of course. Between 2015 and 2017, traffic stops tripled in the city of Chicago and Black drivers saw a disproportionate share of the increase. In 2015, they comprised $49 \%$ of traffic stops; in 2017, they comprised 60\% (ACLU of Illinois, 2019a).

In addition to racially-biased policing at an individual level, evidence exists for disparities at the neighborhood level. In many cases, the patterns of traffic stops reflect a policing strategy that seeks to impose order on "disorganized" neighborhoods. One way this is theorized is via the racial threat hypothesis, which suggests that those in power seek to impose greater control on the Black population as it grows (e.g. Eitle et al., 2002). Implicitly, this is reflected in statistics that show either a greater number of stops in neighborhoods of color or low socioeconomic status neighborhoods, or by regulating belonging. In an unidentified city in the Southwestern United States, researchers found that regardless of race, gender, or resident status of the drivers, more traffic citations were issued in neighborhoods with lower residential stability, higher poverty rates, and higher proportions of Black and Latino residents (Ingram, 2007). Others also find evidence for a "race-out-of-place" theory, where people are more likely to be scrutinized if they do not match the majority demographics of the neighborhood. For example, out of 52,165 traffic stops in Kansas City, Missouri, more searches were conducted in neighborhoods with a higher share of renters or a higher share of Black residents (Novak and Chamlin, 2012). White residents were also more likely to be stopped in a Black neighborhood, as were Black residents in a white neighborhood. Similar patterns were found in St. Louis, Missouri (Rojek et al., 2012). 
Explicitly, an aggressive policing strategy is reflected in policies such as Broken Windows policing and related strategies that seek to deter crimes by aggressively enforcing minor infractions, including pedestrian or bicycle violations. Several authors have argued that a zero-tolerance policing strategy that has been associated with a reduction in violent crime, especially that employed by the New York City Police Department in the 1990s and 2000s, reduced quality of life and limited the mobility of people of color (Howell, 2016; Kaufman, 2016; Lieberman and Dansky, 2016). When police departments shift their traffic enforcement efforts to focus on safety violations and reduce the number of discretionary violations they flag, they eliminate the racial disparities in stops and citations (Fliss et al., 2020).

Few academic studies have examined the enforcement of bicycle infractions specifically, but several journalists have documented disparities. The Chicago Police Department issued a disproportionate number of bicycle tickets in majority Black and Latino neighborhoods, actions they justified as part of their violence reduction strategies (Greenfield, 2018). Until recently, riding a bicycle on the sidewalk was one of the top four most common summonses issued by the New York City Police Department (Levine and Siegel, 2014; New York City Police Department, 2015). Most tickets were given in majority Black or Latino neighborhoods. More recently, $86 \%$ of tickets for biking on the sidewalk in New York City in the past two years were given to Black and Latino cyclists (Cuba, 2020). One academic study of bicycle stops in Tampa, Florida, found that large racial disparities in stops were uncorrelated with bicycle safety incidents but were associated with neighborhood crime rates (Mitchell and Ridgeway, 2018). 


\subsection{Cycling safety and sidewalk riding}

Dedicated cycling infrastructure has objective benefits for cyclist safety. In general, cyclists who use on-street infrastructure such as cycle tracks, bike lanes, and bicycle-priority streets have lower odds of getting into a crash or sustaining injuries relative to cycling in mixed traffic (Bhatia et al., 2016; Reynolds et al., 2009; Teschke et al., 2012). Facilities that are physically separated from traffic lower the risk of crash or injury the most, though precise effects are difficult to discern because studies are not consistent in how they measure safety improvements (DiGioia et al., 2017). Cyclists perceive separated infrastructure to be safer, too, which can lead to higher rates of cycling (Buehler and Dill, 2016; Monsere et al., 2012; Pucher et al., 2010). That enhances safety in turn, because the rates of crashes and serious injuries decline as the number of cyclists on roadways increases (Elvik and Bjørnskau, 2017; Jacobsen, 2003).

Not all cycling infrastructure is the same, however. Cyclists may use sidewalks if there is no dedicated road space for them when traveling on major, high traffic roads, especially if they are timid or less confident in their cycling abilities (Aultman-Hall and Adams, 1998; Kang and Fricker, 2013). But cyclists are not necessarily safer on sidewalks. A study of 2,468 cyclists in Toronto and Ottawa, Canada, found a higher incidence rate of collisions, falls, and injuries on sidewalks compared to other infrastructure types (Aultman-Hall and Adams, 1998). A survey of 690 injured cyclists in Vancouver, Canada, found a sharp divergence in how they perceived the safety of sidewalks (i.e., about $40 \%$ thought sidewalk riding was somewhat or very dangerous, and about $50 \%$ thought it safe or very safe), yet the odds ratio of incidents on sidewalks was higher than most other types of streets with bicycle infrastructure (Winters et al., 2012). A review of 23 studies on cycling safety estimates that the risk of collisions while riding on the 
sidewalk is 1.8 to 16 times that of riding on the road - a wide range to be sure, but all indicating that sidewalks carry more danger for cyclists (Reynolds et al., 2009).

In many—but not all—places, riding a bicycle on the sidewalk is illegal for adults owing to potential conflicts with other street users. Cyclists pose a danger to pedestrians because they move at three to four times their speed, and they face danger from vehicles when sidewalks pass across driveways and intersections. Yet cyclists will knowingly (or unknowingly) break rules when they perceive it to be safer than the alternative. Researchers conducted a global survey of 17,851 people to understand law-breaking behavior across all modes of transportation. Nearly all respondents reported breaking a traffic rule regardless of travel mode; the most common reason cyclists did so was for personal safety (Marshall et al., 2017). A study of cyclists in Montreal, Canada, found that only $0.6 \%$ of survey respondents consistently followed all traffic laws (Chaloux and El-Geneidy, 2019). Given a set of four hypothetical scenarios, cyclists most often chose to break a traffic rule when they felt it was safer than precisely following the vehicle code. Sidewalk cycling is likely to be a behavioral adaptation in response to inequitable infrastructure. For example, focus groups with predominately Black residents of south side neighborhoods in Chicago expressed frustration with receiving citations when there was no safe alternative to the sidewalk (Coren and Lowe, 2020). Cyclists generally break traffic rules for rational reasons.

\subsection{Not all safety is created equal}

Structural conditions create more dangerous environments for cyclists of color. In Chicago, for example, a 2015 analysis found that presence of bicycle infrastructure was correlated with wealthier, whiter neighborhoods (Prelog, 2015). Lower socioeconomic status communities have less access to infrastructure as a result of historical disinvestment (Braun et al., 2019; Cradock et 
al., 2009). This in turn can create dangerous conditions for cycling, even when bicycle lanes are eventually provided. In the San Francisco Bay Area, for example, one study found that Black cyclists were disproportionately at risk of being involved in crashes in high-poverty neighborhoods, but streets that had bicycle infrastructure and lower traffic volumes did not reduce cyclists' risks of being involved in a crash (Barajas, 2018).

Apart from inadequate protection from cars, Black cyclists face other barriers to personal safety and security. Multiple studies with Black participants have found that not feeling safe from crime was a common barrier to cycling (Brown et al., 2016; Schneider et al., 2018). In Boston, cyclists from low-income neighborhoods and neighborhoods of color preferred cycling on highly visible streets — often those with greater traffic volumes - rather than traveling on streets with adequate bicycle infrastructure because protection from crime was more salient to them (Lusk et al., 2019). By one estimate, a reduction in crime by $1 \%$ per census tract would result in a $2.1 \%$ increase in bike ridership (Caros and Chow, 2020). Racial profiling by the police was another common barrier for Black and Latino cyclists in New Jersey (Brown et al., 2016), while Detroit, Tampa, and Chicago all have documented instances of disproportionate policing against Black cyclists (Hoffmann, 2016; Wisniewski, 2018, 2017).

The evidence for the benefits of cycling infrastructure with respect to safety are clear, as is the evidence for racial disparities in both provision of that infrastructure and police enforcement of traffic laws. There has been little examination of the intersection of the two domains. Where there is evidence that a lack of safe cycling spaces might contribute to disparities in enforcement, planners might use their positions to advocate for explicitly anti-racist policies for infrastructure provision to eliminate the harmful effects. 


\section{Chicago context}

The setting for this study is the city of Chicago. Chicago is a racially diverse yet starkly segregated city of 2.7 million people. The population is $33 \%$ white, $30 \%$ Black, $29 \%$ Latino, and $6 \%$ Asian; segregation indexes of the region rank within the top 10 of all commuting zones in the country (Acs et al., 2017). The south side of the city, which is majority Black, has comparatively worse access to jobs and other opportunities by all travel modes compared to other areas of the city. Chicago has over 200 miles of bicycle lanes with 645 planned as of 2012, the most recently released bicycle plan (Chicago Department of Transportation, 2012), but the infrastructure is disproportionately absent from neighborhoods of color, particularly on the south side. Bicycling accounts for $1.6 \%$ of commute trips, for which the city ranks 13th of large cities (League of American Bicyclists, 2020).

The Chicago Police Department has long struggled with discriminatory policing and causing disproportionate harm in communities of color in general, and in Black communities specifically. The Illinois Torture Inquiry and Relief Commission was established in 2009 to investigate the credible claims that CPD had tortured people in custody to elicit confessions (State of Illinois, 2020). Evidence indicates that 125 African Americans were tortured by police during the 1970s and 1980s, and currently 400 cases are before the commission pending investigation (Ralph, 2020). Less insidious practices have also had significant negative impacts for Black people. In an analysis on how CPD uses stop-and-frisk, a practice in which police stop individuals whom they have a reasonable suspicion of carrying weapons or having committed a crime, the American Civil Liberties Union found in 2014 that the CPD stopped 9.4 out of every 100 people, a rate four times higher than New York City in 2011 at the height of their own stopand-frisk program (Illinois, 2015). Nearly three quarters of those stopped in Chicago were Black. 
The report led to a negotiated agreement between the ACLU and the CPD in which the department would collect and report data more transparently and would train officers on the correct legal conditions for investigatory stops ("Investigatory Stop and Protective Pat Down Settlement Agreement," 2015). And yet CPD is today under a federal consent decree to institute comprehensive reforms to their use of force, community policing, hiring, data management, and other aspects of operations (Illinois Attorney General, 2019).

These discriminatory practices extend to bicycle enforcement as well. Between 2008 and 2016, the top 10 neighborhoods for tickets issued were all majority Black or Latino, and twice the number of tickets were issued in majority Black neighborhoods as in majority Latino or white neighborhoods (Wisniewski, 2018, 2017). A decreasing number of tickets have been issued since the ACLU-CPD agreement went into effect in 2017 (see Figure 1). At the same time, the gap between majority Black neighborhoods and others has been narrowing but as of 2019, Black neighborhoods still received a disproportionate number of tickets (Wisniewski, 2019). 


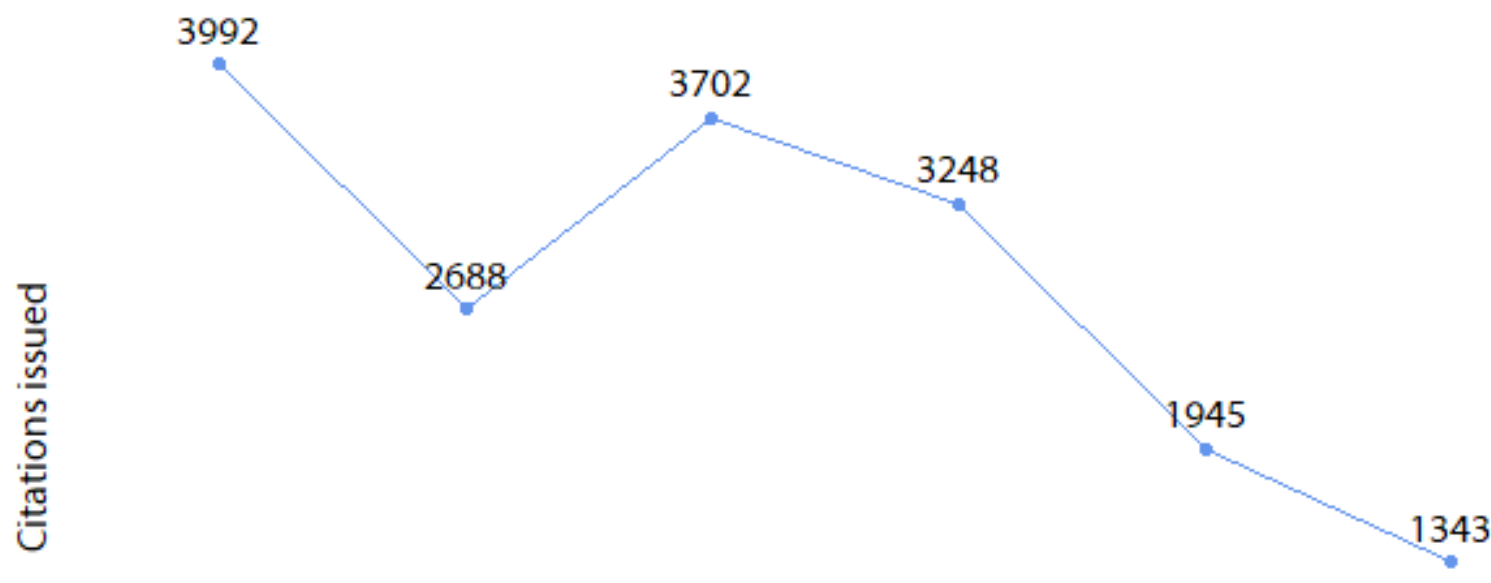

\begin{tabular}{llllll}
\hline 2014 & 2015 & 2016 & 2017 & 2018 & 2019
\end{tabular}

Figure 1: Citations for cycling on the sidewalk per year

\section{Data and methods}

\subsection{Data}

This study relies on multiple data sources, including police stops, street infrastructure, neighborhood characteristics, and cycling volume. (See Table 1 for a summary.) Via a Freedom of Information Act request, I obtained a dataset of citations issued by the Chicago Police Department (CPD) for bicycle-related offenses that occurred within city limits between January 2017 and December 2019. ${ }^{1}$ The original dataset included all citations, but the analysis for this

${ }^{1}$ The citation data are publicly available at https://doi.org/10.17605/osf.io/t6gjh/. The posted dataset includes citations beginning from January 2014. 
study includes only citations issued for cycling on the sidewalk. This is for several reasons. First, sidewalk cycling was the most commonly issued citation by far: $90 \%$ of all bicycle-related offenses consisted of citations for riding on the sidewalk. Second, it is an offense that can be linked to the presence or absence of bicycle infrastructure. Third, as described elsewhere, CPD has explained that issuing tickets for bicycle offenses is part of their overall strategy for crime reduction, and thus there is a muddled link between traffic stops and enforcing safety violations that is necessary to examine.

The dataset of bicycle citations included the time, date, and street block where the stops occurred, accurate to the block face. Because CPD did not release the exact addresses of the stops, we did not geocode stops to points in space but rather matched the citations to a street segment by address range in the City of Chicago street centerline file. If there were multiple segments within the same address range, we randomly assigned the citation to one of the street segments. Using this technique, we were able to match $98 \%(n=16,918)$ of citations to the street network.

Infrastructure data included information about bicycle facilities and roadway functional classification from the City of Chicago. Bicycle facilities were classified into three types: onroad facilities, which included signed bike routes and neighborhood greenways; bike lanes, including traditional bike lanes and buffered bike lanes; and separated bike lanes, such as cycle tracks and off-street paths. These data were spatially joined to the street database. Roadway functional classification stood in as a proxy for traffic volume. The street database was filtered to include only arterial, collector, and local streets. Larger streets like expressways are prohibited to non-motorized vehicles, while other street types like alleyways or recreational pathways would 
not have sidewalks on which to have tickets issued. Functional class is an imperfect proxy; actual traffic counts would be a better theoretical representation of potential danger to cyclists but such information was unavailable for most city streets. There is a general correspondence between functional class and traffic volume, but it is likely that in some neighborhoods - particularly those in which the population has declined and investment has moved out—streets are overbuilt for present-day capacity needs. In these cases, functional class may more accurately represent risk of injury severity from vehicles traveling higher speeds rather than crash incidence. ${ }^{2}$ In either case, the impetus for improving safety remains. Future research might incorporate both traffic volume and speed as variables of interest to determine relative effects and priority locations to address safety.

Neighborhood characteristics aggregated to the census tract level included sociodemographic data from the American Community Survey (ACS), employment density from the Longitudinal Employer-Household Dynamics program, and policing and safety data from city sources. Sociodemographic characteristics included race/ethnicity, poverty, and population density. I obtained data on the average number of sworn officers assigned to each police district from the Chicago Office of the Inspector General. Because districts encompass multiple census tracts, I assigned the total average annual number of officers to each tract within the district. I also obtained data on the average annualized number of violent crimes per tract. Violent crimes use the definition provided by the Federal Bureau of Investigation Uniform Crime Reporting

\footnotetext{
${ }^{2}$ For example, early evidence indicates that the median speed on principal arterials and major collectors increased $5-10 \%$ between June and December 2020 when traffic volumes were significantly lower as a result of the Covid-19 pandemic (National Highway Traffic Safety Administration, 2021).
} 
codes. Finally, the analysis considered the number of bicycle crashes that caused severe injuries or death as a key variable of interest, in addition to the number of traffic crashes involving any type of vehicle. Infrastructure data came from the most recent snapshot available (2019, the end of the 2017-2019 study period). Safety, crime, and officer assignments used data from the most recent three-year period. Since serious and fatal crashes are rare, I used the total number of crashes over the period, whereas for the other variables I used the average over the period to smooth out variance.

\subsection{Cycling exposure}

I used three data sources to estimate bicyclist exposure to potential policing actions. The first is the 2019 average annual daily bicycle (AADB) volume from the Strava Metro database. AADB is calculated per link by matching OpenStreetMap links to the Chicago street centerline file. The second is the bicycle commute share at the census tract level from the five-year 2015-2019 ACS. ${ }^{3}$ The third is the weighted number of bicycle trips per census tract from the Chicago Metropolitan Agency for Planning (CMAP) 2018-2019 household travel survey. The CMAP survey data are weighted to three zones within Chicago; I allocated the zonal trips proportionally by population to each census tract.

Each method has its advantages and disadvantages. Strava Metro data can be assigned to each roadway link, leading to a realistic distribution of cycling activity at a micro scale. However, Strava does not encompass all cycling activity done by all people. While it does

\footnotetext{
${ }^{3}$ Because many tracts reported no cycling to work, I added 0.1 percent to each record ensure observations were not dropped from the statistical models.
} 
contain both utilitarian and recreational trips, users must possess a fitness tracker and opt in to data reporting. The data represent up to five percent of total cycling volume and tend to overrepresent white, middle-aged men (Lee and Sener, 2020; Nelson et al., 2020). Research has shown that, with adjustment, Strava Metro data can predict cycling volumes with under 30 percent measurement error (Dadashova et al., 2020). But others have shown that the data by themselves serve as reasonable proxies for cycling exposure (Lee and Sener, 2020), and so I use the Strava data here without adjustment. Both ACS and CMAP travel survey data have the advantages of being more representative of the population but can only be applied over zones rather than over road segments. ACS bicycling data contain only commute share in the home census tract and suffer from relatively large margins of error but are comprehensive for the city. The CMAP travel survey data contain trips for any purpose and for any origin but are weighted to be representative of larger areas; allocating data to census tracts introduces inaccuracies. For simplicity in presentation, in the main text I describe only the model using AADB as the control for cycling exposure and discuss the other two models in Section 5.3. 
Table 1: Summary statistics and data sources

\begin{tabular}{|c|c|c|}
\hline Characteristic & Summary statistics ${ }^{\prime}$ & Source (vintage) $)^{2}$ \\
\hline \multicolumn{3}{|l|}{ Street segment characteristics } \\
\hline Sidewalk bicycling citations & $0.13(0.85)$ & CPD (2017-2019) \\
\hline Bicycle facility & & City of Chicago (2019) \\
\hline None & $47,572(93 \%)$ & \\
\hline Sharrow/Route & $670(1.3 \%)$ & \\
\hline Bike lane & I,255 (2.5\%) & \\
\hline Separated facility & I,558 (3.1\%) & \\
\hline Functional classification & & City of Chicago (2019) \\
\hline Local street & $37,831(74 \%)$ & \\
\hline Arterial & $6,265(12 \%)$ & \\
\hline Collector & $6,959(14 \%)$ & \\
\hline Street length $(\mathrm{km})$ & $0.4 \mathrm{I}(0.20)$ & City of Chicago (2019) \\
\hline Average annual daily bicycle volume & I.I (5.0) & Strava Metro (2019) \\
\hline \multicolumn{3}{|l|}{ Tract characteristics } \\
\hline White (\%) & $31(30)$ & ACS (2015-2019) \\
\hline Black (\%) & $36(40)$ & ACS (2015-2019) \\
\hline Latino (\%) & $26(29)$ & ACS (2015-2019) \\
\hline Asian (\%) & $5.7(9.4)$ & ACS (2015-2019) \\
\hline Poverty (\%) & $21(14)$ & ACS (2015-2019) \\
\hline Population density $\left(\mathrm{I} / \mathrm{km}^{2}\right)$ & $7,253(6,040)$ & ACS (2015-2019) \\
\hline Employment density $\left(\mathrm{I} / \mathrm{km}^{2}\right)$ & $2,848(13,423)$ & LEHD (2017) \\
\hline Serious/fatal bike crashes & $3.2(4.5)$ & City of Chicago (2017-2019) \\
\hline Serious/fatal traffic crashes & $32(29)$ & City of Chicago (2017-2019) \\
\hline Mean police officers assigned & $34 \mid(52)$ & City of Chicago OIG (2017-2019) \\
\hline Bicycle commute share (\%) & $1.6(2.2)$ & ACS $(2015-2019)$ \\
\hline Number of bicycle trips & $188(2 \mid \mathrm{I})$ & CMAP Travel Survey \\
\hline Mean annual violent crimes & $210(199)$ & City of Chicago (2016-20I8) \\
\hline
\end{tabular}

\subsection{Methods}

I estimated a multilevel negative binomial regression model to examine the influence of street and safety characteristics on citations, controlling for sociodemographics, neighborhood policing, and cycling activity. The dependent variable for the model is the total number of sidewalk cycling citations issued along each street segment. Key explanatory independent variables include dummy variables for the type of bicycle infrastructure present on a street 
segment (none, bike route, bike lane, or separated bike lane) and the functional class of the roadway (local, collector, or arterial). The models include interaction terms between bicycle infrastructure and functional class to test whether the number of citations issued varies across the combination of infrastructure types. Control variables of the population include the share of the census tract population who are Black, Latino, and Asian, the percentage in poverty, the logged population density, and the logged employment density. Neighborhood control variables include two measures of traffic safety - the total number of serious or fatal vehicle and bicycle crashesand the annual number of violent crimes. Models also control for the annual number of police officers assigned to the district in which the census tract was located. Models also control for street length.

Negative binomial models are appropriate when the dependent variable is a count, when the actual counts are far below a theoretical maximum, and when the variance is not expected to be equal to the mean. The distribution of the sidewalk cycling citations met these characteristics. Multilevel, or hierarchical, models are necessary when one unit of analysis is nested within another unit of analysis, accounting for both variation between the higher-order groups and for errors when multiple observations are associated with the same set of higher-level characteristics (Gelman and Hill, 2007). In the case of this study, the unit of analysis for the dependent variable is the street segment, which is nested within census tracts. Street segments carry characteristics of the number of citations issued, bicycle facility type, functional classification, and cycling volume. All other data is specified at the census tract level.

I estimated the simplest version of a multilevel model with varying intercepts for each census tract, sometimes also known as a fixed effects model. The model coefficients, shown 
exponentiated as incident rate ratios in Section 5.2, represent the effects of each variable on the expected rate of tickets over the time period regardless of tract. The predicted number of tickets would need to account for the intercept associated with the census tract. Models were estimated using the glmmTMB package in R (Brooks et al., 2017).

\section{Findings}

\subsection{What are the disparities in bicycle citations and associated characteristics?}

Descriptive statistics indicate the extent of the disparities in bicycle citations issued (Table 2). An average of 2.9 bicycle citations per 1,000 people were issued per census tract over the study period. Census tracts with a majority Black population saw an average of 5.9 tickets issued per 1,000 people, three times more than the average issued in majority Latino neighborhoods and eight times more than were issued in majority white neighborhoods. The high number of tickets in majority Black neighborhoods came despite having the fewest serious bicycle crashes, defined as those where the cyclist was killed or had an evident injury. Black neighborhoods, however, had the highest number of serious crashes of all modes on average. Black and Latino neighborhoods had higher shares of arterial streets, although the difference from other groups was not statistically significant. The same groups also had higher shares of streets without bicycle infrastructure compared to majority Asian or white census tracts. In tracts where there was no racial or ethnic majority, those where Latinos made up the greatest share of the population had the highest average number of tickets.

A descriptive spatial analysis reveals the geography of these patterns. The distribution of sidewalk cycling tickets was concentrated primarily in majority Black neighborhoods on the west side and south side (Figure 2). There was little apparent correlation between dangerous locations 
for cyclists and where tickets were issued (Figure 3). Most bicycle injury crashes occurred in the neighborhoods surrounding Milwaukee Ave., a major cycling thoroughfare, whereas comparatively few bicycle tickets were issued in the same location. These patterns suggest that bicycle tickets are only weakly associated with safety needs, if at all. 
Table 2: Comparison of key variables by neighborhood racial composition

\begin{tabular}{|c|c|c|c|c|c|c|c|c|c|c|}
\hline \multirow[b]{2}{*}{ Characteristic } & \multirow[b]{2}{*}{$\begin{array}{l}\text { Overall, } \\
N=800^{\prime}\end{array}$} & \multicolumn{4}{|c|}{ Tracts with racial majority } & \multicolumn{4}{|c|}{ Tracts with no racial majority } & \multirow[b]{2}{*}{$\begin{array}{c}\mathrm{P}- \\
\text { value }^{3}\end{array}$} \\
\hline & & $\begin{array}{c}\text { Majority, } \\
\text { Asian, } N= \\
6^{1}\end{array}$ & $\begin{array}{c}\text { Majority, } \\
\text { Black, N = } \\
277^{\prime}\end{array}$ & $\begin{array}{c}\text { Majority, } \\
\text { Latino, } \mathrm{N}= \\
170^{\prime}\end{array}$ & $\begin{array}{c}\text { Majority, } \\
\text { White, } N= \\
242^{\prime}\end{array}$ & $\begin{array}{l}\text { Plurality, } \\
\text { Asian, } N= \\
6^{12}\end{array}$ & $\begin{array}{c}\text { Plurality, } \\
\text { Black, } \mathrm{N}= \\
15^{12}\end{array}$ & $\begin{array}{l}\text { Plurality, } \\
\text { Latino, } N= \\
24^{12}\end{array}$ & $\begin{array}{c}\text { Plurality, } \\
\text { White, } N= \\
60^{12}\end{array}$ & \\
\hline $\begin{array}{l}\text { Bike citations per } \\
1000\end{array}$ & $2.9(5.4)$ & $0.4(0.6)$ & $5.9(7.5)$ & $1.9(2.9)$ & $0.7(1.3)$ & $0.5(0.5)$ & $1.1(1.2)$ & $2.7(5.4)$ & $1.3(4.0)$ & $<0.001$ \\
\hline $\begin{array}{l}\text { Serious bike } \\
\text { crashes }\end{array}$ & $3.2(4.5)$ & $4.7(4.1)$ & $1.6(2.0)$ & $2.8(2.5)$ & $5.1(6.6)$ & $5.3(5.0)$ & $2.2(2.2)$ & $3.4(3.1)$ & $4.4(4.6)$ & $<0.001$ \\
\hline $\begin{array}{l}\text { Serious crashes } \\
\text { (all modes) }\end{array}$ & $32(29)$ & $26(28)$ & $36(24)$ & $29(19)$ & $32(37)$ & $4 \mid(23)$ & $30(36)$ & $24(12)$ & $32(37)$ & $<0.001$ \\
\hline $\begin{array}{l}\text { Mean officers } \\
\text { assigned (annual) }\end{array}$ & $34 \mid(52)$ & $363(8)$ & $368(42)$ & $347(43)$ & $316(54)$ & 327 (39) & $348(27)$ & $289(54)$ & $310(45)$ & $<0.001$ \\
\hline $\begin{array}{l}\text { Mean violent } \\
\text { crimes (annual) }\end{array}$ & $210(183)$ & $127(118)$ & $296(150)$ & $16 \mid(87)$ & $169(244)$ & $200(127)$ & I8I (107) & $148(77)$ & $167(153)$ & $<0.001$ \\
\hline $\begin{array}{l}\text { Local streets (\% } \\
\text { length) }\end{array}$ & $\begin{array}{l}77.3 \\
(11.4)\end{array}$ & $80.9(10.2)$ & $77.4(10.4)$ & $80.3(9.0)$ & $75.0(13.4)$ & $81.7(7.4)$ & $75.3(12.0)$ & $76.9(9.1)$ & $77.1(13.0)$ & 0.005 \\
\hline $\begin{array}{l}\text { Collector streets } \\
\text { (\% length) }\end{array}$ & $\begin{array}{c}12.8 \\
(10.2)\end{array}$ & $10.8(9.1)$ & $12.0(9.7)$ & $10.0(7.7)$ & $15.6(12.0)$ & $8.5(6.7)$ & $12.8(8.9)$ & $12.6(9.6)$ & I3.7 (9.9) & $<0.001$ \\
\hline $\begin{array}{l}\text { Arterial streets } \\
\text { (\% length) }\end{array}$ & $9.9(7.8)$ & $8.4(3.8)$ & $10.6(7.0)$ & 9.7 (7.8) & $9.4(8.7)$ & $9.8(5.5)$ & $11.9(10.5)$ & $10.5(7.2)$ & $9.2(7.7)$ & 0.2 \\
\hline $\begin{array}{l}\text { No bike facilities } \\
\text { (\% length) }\end{array}$ & $93.0(9.0)$ & $87.8(9.5)$ & 93.9 (8.6) & $96.2(5.7)$ & $91.2(9.4)$ & $91.2(12.4)$ & $90.9(10.4)$ & $92.6(8.4)$ & $88.1(12.1)$ & $<0.001$ \\
\hline $\begin{array}{l}\text { Bike routes (\% } \\
\text { length) }\end{array}$ & I.5 (3.9) & $0.0(0.0)$ & $0.4(1.7)$ & $1.2(3.1)$ & $2.1(4.7)$ & $0.2(0.5)$ & $2.1(3.8)$ & $3.9(7.7)$ & $3.8(5.9)$ & $<0.001$ \\
\hline
\end{tabular}




\begin{tabular}{|c|c|c|c|c|c|c|c|c|c|c|}
\hline \multirow[b]{2}{*}{ Characteristic } & \multirow[b]{2}{*}{$\begin{array}{l}\text { Overall, } \\
\mathrm{N}=800^{\prime}\end{array}$} & \multicolumn{4}{|c|}{ Tracts with racial majority } & \multicolumn{4}{|c|}{ Tracts with no racial majority } & \multirow[b]{2}{*}{$\begin{array}{c}\text { P- } \\
\text { value }^{3}\end{array}$} \\
\hline & & $\begin{array}{c}\text { Majority, } \\
\text { Asian, } N= \\
6^{1}\end{array}$ & $\begin{array}{c}\text { Majority, } \\
\text { Black, N = } \\
277^{1}\end{array}$ & $\begin{array}{c}\text { Majority, } \\
\text { Latino, } \mathrm{N}= \\
170^{1}\end{array}$ & $\begin{array}{c}\text { Majority, } \\
\text { White, } \mathrm{N}= \\
242^{\prime}\end{array}$ & $\begin{array}{c}\text { Plurality, } \\
\text { Asian, } \mathrm{N}= \\
6^{12}\end{array}$ & $\begin{array}{c}\text { Plurality, } \\
\text { Black, } \mathrm{N}= \\
15^{12}\end{array}$ & $\begin{array}{c}\text { Plurality, } \\
\text { Latino, } N= \\
24^{12}\end{array}$ & $\begin{array}{c}\text { Plurality, } \\
\text { White, } \mathrm{N}= \\
60^{12}\end{array}$ & \\
\hline $\begin{array}{l}\text { Bike lanes (\% } \\
\text { length) }\end{array}$ & $5.0(7.7)$ & $10.4(7.6)$ & $5.1(7.7)$ & $2.4(4.6)$ & $6.2(8.2)$ & $3.5(5.6)$ & $6.0(9.5)$ & $3.2(4.7)$ & $7.4(10.6)$ & $<0.001$ \\
\hline $\begin{array}{l}\text { Separated bike } \\
\text { facilities (\% } \\
\text { length) }\end{array}$ & $0.5(2.1)$ & $\mathrm{I} .8(2.3)$ & $0.6(2.2)$ & $0.2(1.6)$ & $0.4(1.9)$ & $5.1(8.0)$ & $\mathrm{I} .0(2.3)$ & $0.3(1.4)$ & $0.7(1.9)$ & $<0.001$ \\
\hline $\begin{array}{l}\text { Total street } \\
\text { segment length } \\
(\mathrm{km})\end{array}$ & $26(18)$ & $21(12)$ & $29(17)$ & $26(15)$ & $25(20)$ & $24(9)$ & $22(28)$ & $21(12)$ & $23(17)$ & $<0.001$ \\
\hline
\end{tabular}

'Mean (SD)

${ }^{2}$ Notes: Race/ethnicity identified under "Plurality" is the largest group in that tract when it is less than $50 \%$ of the population. Serious crashes defined as those resulting in fatalities, incapacitating injuries, or non-incapacitating but evident injuries.

${ }^{3}$ Kruskal-Wallis rank sum test 


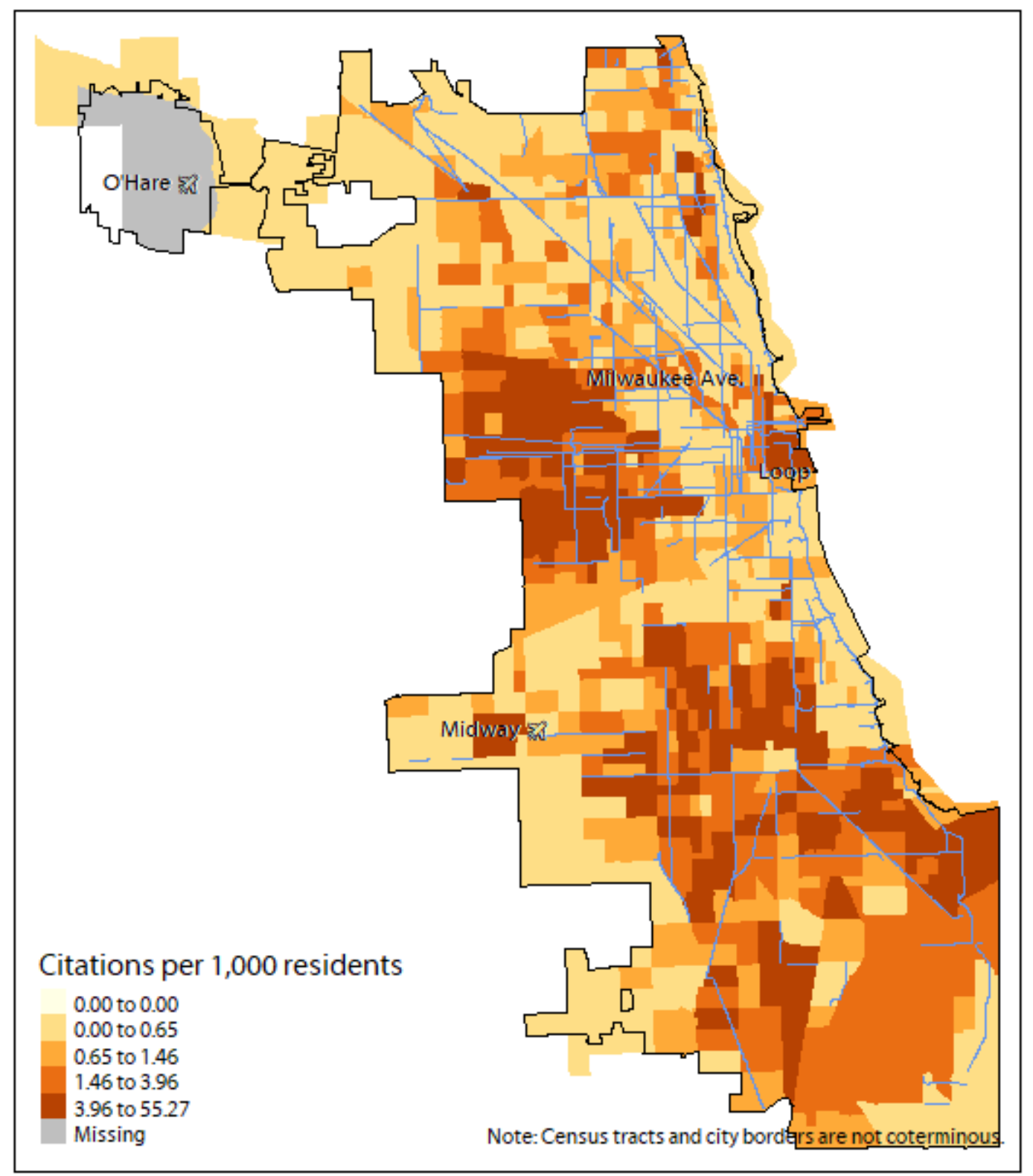

Figure 2: Distribution of sidewalk cycling citations with bicycle infrastructure 


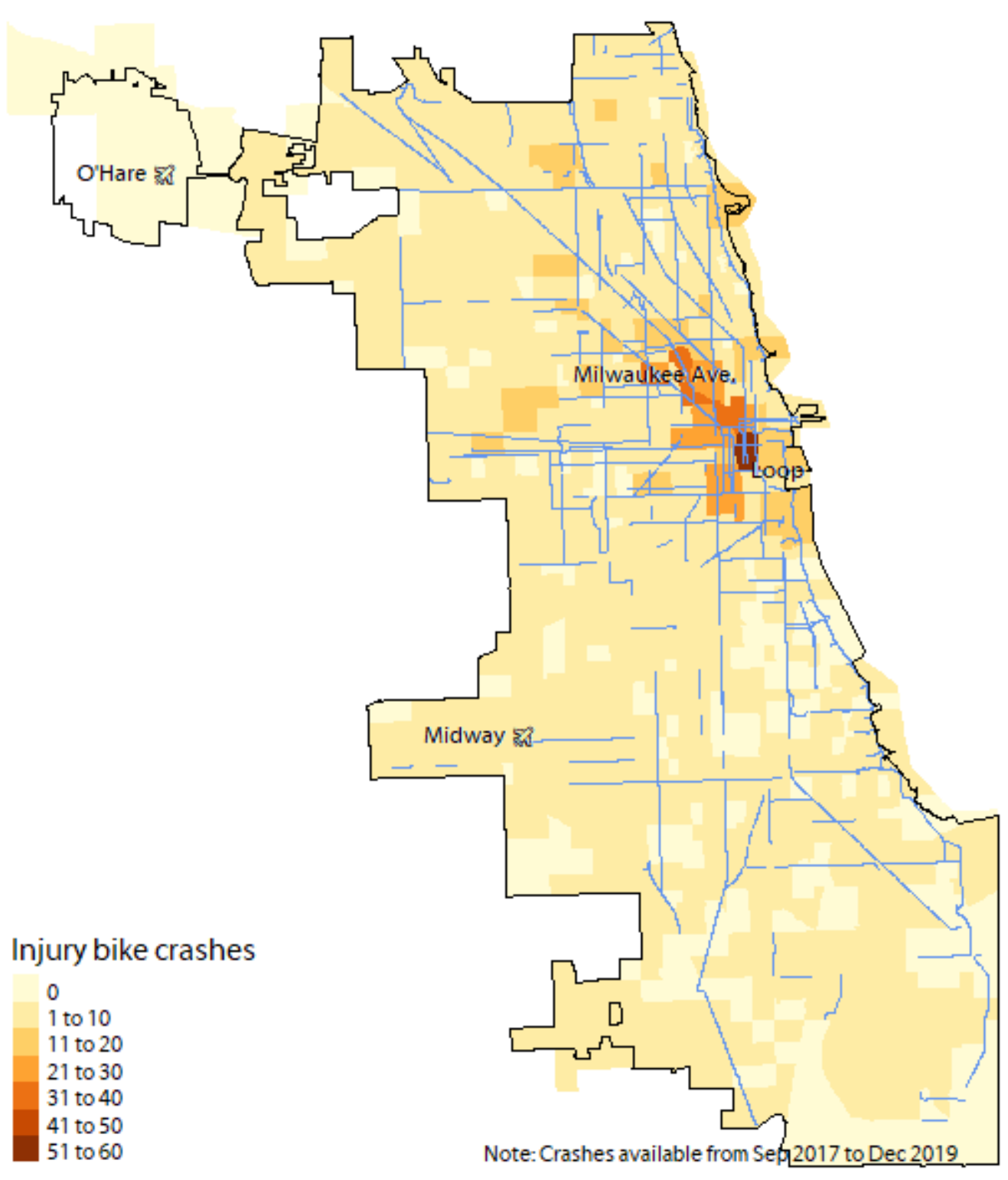

Figure 3: Bicycle crashes per census tract in Chicago with bicycle infrastructure, 2017-2019

\subsection{How is infrastructure implicated in policing inequities?}

The key set of variables in the statistical model tested the relationships between street infrastructure and bicycle citations (Table 3). Tickets were more likely to be issued on busier streets. On streets without bicycle infrastructure, the rate of tickets issued to cyclists was 15 
times higher on arterial roads and 7 times higher on collector streets compared to local streets, adjusting for street segment length and bicycle volume. These street types comprised about 23\% of the total non-freeway street length in the city, yet accounted for $71 \%$ of tickets issued. These patterns suggest that cyclists are more likely to ride on the sidewalk on busier roads, placing them at a higher likelihood of receiving a ticket. The higher rate of ticketing may also be exacerbated by heavier police patrols on arterial and collector streets, though the data available do not allow for confirmation.

The analysis of street functional class together with bicycle facility type suggests the extent to which bicycle infrastructure might reduce the incidence of citations. When major streets had any kind of bicycle infrastructure, the rate of tickets issued decreased by up to $85 \%$ from the baseline, as reflected by the interaction terms in the model. For example, cyclists received tickets $54 \%$ as often on arterial streets with bike lanes compared to arterial streets without bike lanes, and $47 \%$ as often on collector streets with bike lanes compared to collector streets without. Separated lanes appeared to have the strongest effects. On arterial streets, cyclists received citations $25 \%$ as often when there was a separated lane compared to no bicycle infrastructure, although the estimate was just outside the $95 \%$ confidence interval. On collector streets, cyclists received citations $15 \%$ as often compared to streets without bicycle infrastructure. Curiously, onstreet facilities on arterial streets, which are exclusively shared lanes, were also associated with a large decrease in the rate of tickets issued, on par with the effects of separated facilities. Most shared lanes on arterial streets in Chicago are used to fill gaps between other bicycle facility types, so this finding may reflect either a sort of spillover effect from other lane types or their relative rarity compared to bike lanes. The baseline (non-interacted) terms for bicycle facility 
type reflect infrastructure effects on local roads. In these cases, bicycle infrastructure was associated with a higher incidence of tickets, statistically significantly so at the $95 \%$ confidence interval for on-street facilities, but not for bike lanes and separated infrastructure. This may indicate that even on lower-volume streets, shared lanes are not enough to help cyclists feel safe from vehicles.

Indicators of neighborhood disadvantage were associated with higher numbers of bicycle citations issued per street segment, consistent with expectations. Of the socioeconomic control variables, tickets were most strongly associated with neighborhood poverty. For every percentage point increase in the census tract poverty rate, the rate of citations issued for cycling on the sidewalk increased by $3.0 \%$ per street segment. All else equal, the rate of tickets issued was also positively associated with greater shares of the Black and Latino population, but not significantly associated with the share of the Asian population. Recall that the demographic characteristics apply at the census tract level. In other words, regardless of infrastructure, cyclists are more likely to get a ticket in a neighborhood of color compared to a majority white neighborhood. The other population-related characteristics tested, namely population and employment density, were both positively associated with tickets, reflecting how intensity of activity increases the probability of encounters with the police.

The third set of variables controlled for characteristics related to the enforcement context, including crashes and police presence. The number of crashes involving cyclists who were killed, severely injured, or visibly injured was unrelated to the number of bicycle tickets issued. Furthermore, the number of serious crashes involving any vehicle type was inversely related to the number of citations to a small but statistically significant degree. The number of tickets was 
positively associated with the number of violent crimes in a neighborhood, holding constant the number of officers deployed in a police precinct. Put together, the trends lend credibility to the claim that issuing tickets for riding bicycles on the sidewalk has not been a tool employed to improve safety outcomes. 


\begin{tabular}{|c|c|c|c|}
\hline & IRR & $95 \% \mathrm{Cl}$ & $\mathrm{P}$-value \\
\hline Black (\%) & 1.022 & $(1.017,1.027)$ & 0.000 \\
\hline Latino (\%) & 1.019 & $(1.014,1.024)$ & 0.000 \\
\hline Asian (\%) & 0.996 & $(0.984,1.007)$ & 0.470 \\
\hline In poverty (\%) & 1.030 & $(1.021,1.038)$ & 0.000 \\
\hline Population density (log) & 2.286 & $(1.978,2.643)$ & 0.000 \\
\hline Employment density (log) & 1.161 & $(1.070,1.26 I)$ & 0.000 \\
\hline \multicolumn{4}{|l|}{ Bike facility type } \\
\hline Bike route & 3.635 & $(1.940,6.814)$ & 0.000 \\
\hline Bike lane & 1.499 & $(0.949,2.367)$ & 0.082 \\
\hline Separated lane & 2.223 & $(0.928,5.329)$ & 0.073 \\
\hline \multicolumn{4}{|l|}{ Street classification } \\
\hline Arterial street & 15.355 & $(13.716,17.190)$ & 0.000 \\
\hline Collector street & 7.268 & $(6.417,8.231)$ & 0.000 \\
\hline \multicolumn{4}{|l|}{ Interaction terms } \\
\hline Bike route $\mathrm{x}$ Arterial & 0.209 & $(0.092,0.472)$ & 0.000 \\
\hline Bike route $\times$ Collector & 0.272 & $(0.130,0.565)$ & 0.000 \\
\hline Bike lane $\times$ Arterial & $0.54 I$ & $(0.321,0.913)$ & 0.021 \\
\hline Bike lane $\times$ Collector & 0.468 & $(0.28 I, 0.778)$ & 0.003 \\
\hline Separated lane $\times$ Arterial & 0.250 & $(0.059,1.052)$ & 0.059 \\
\hline Separated lane $\times$ Collector & 0.148 & $(0.051,0.429)$ & 0.000 \\
\hline Street length $(\mathrm{km})$ & 9.036 & $(7.230,11.292)$ & 0.000 \\
\hline Serious bike crashes & 1.002 & $(0.975,1.029)$ & 0.902 \\
\hline Serious crashes (all modes) & 0.991 & $(0.986,0.997)$ & 0.001 \\
\hline Violent crimes per year & 1.002 & $(1.002,1.003)$ & 0.000 \\
\hline Officers assigned (mean) & 1.000 & $(0.998,1.002)$ & 0.977 \\
\hline Cycling volume (Strava) & 1.015 & $(1.005,1.024)$ & 0.003 \\
\hline Intercept & 0.000 & $(0.000,0.000)$ & 0.000 \\
\hline SD (Intercept) & 0.864 & $(0.249,0.290)$ & \\
\hline $\mathrm{N}$ & 50867 & & \\
\hline sigma & 0.269 & & \\
\hline log lik. & -12949.448 & & \\
\hline $\mathrm{AIC}$ & 25950.897 & & \\
\hline
\end{tabular}

Notes: IRR = Incident rate ratio Reference values: Race $=$ White $(\%) ;$ Bike facility $=$ None; Street functional class $=$ Local street.

I computed the predicted effects of bicycle infrastructure on ticketing for various values of race and ethnicity (Figure 4), holding the rest of the variables at their average values. The results illustrate the outsize influence that neighborhood racial composition plays in the rate of citations issued per street segment—attributable to biased policing — while also showing the role that infrastructure could play in mitigating that bias. As an example, in census tracts where the 
share of the Black population matched the overall city share (30\%), cyclists would be expected to receive 0.22 citations over the three year period per $0.41 \mathrm{~km}$ of street length. By adding a separated bike facility to that same road segment, the expected number of citations would nearly halve to 0.12 . In census tracts with a Black population of $90 \%$, adding a separated bike facility on an arterial street segment would be associated with a reduction from 0.80 citations to 0.44 citations. An illustration of the global magnitude of potential effects across the city is instructive. Using model predictions, if separated bike infrastructure were installed on every street that had at least three citations over the study period (i.e., one per year), majority Black neighborhoods would see a reduction in citations issued from 4078 to 3754 , or a decrease of $8 \% .{ }^{4}$ While this is a small decrease relative to the effects of race on citations issued and is subject to model uncertainty and the feasibility of installing infrastructure on these segments in practice, it does illustrate how a lack of bike facilities contributes to excess policing in neighborhoods of color.

\footnotetext{
${ }^{4}$ Using the original data, the model overpredicted citations by $0.2 \%$ compared to the actual number issued, indicating a relatively good predictive model.
} 


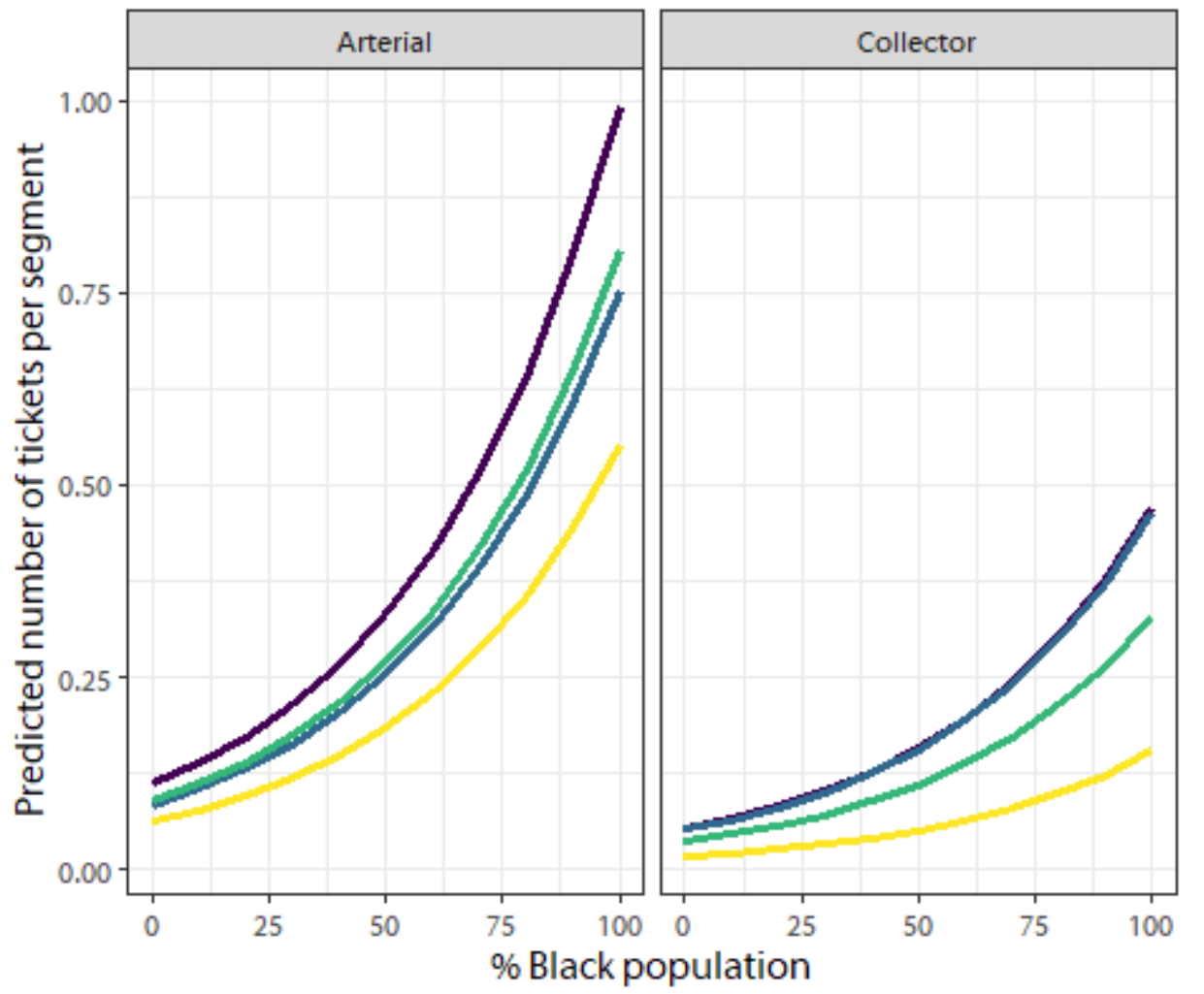

Bike facility type
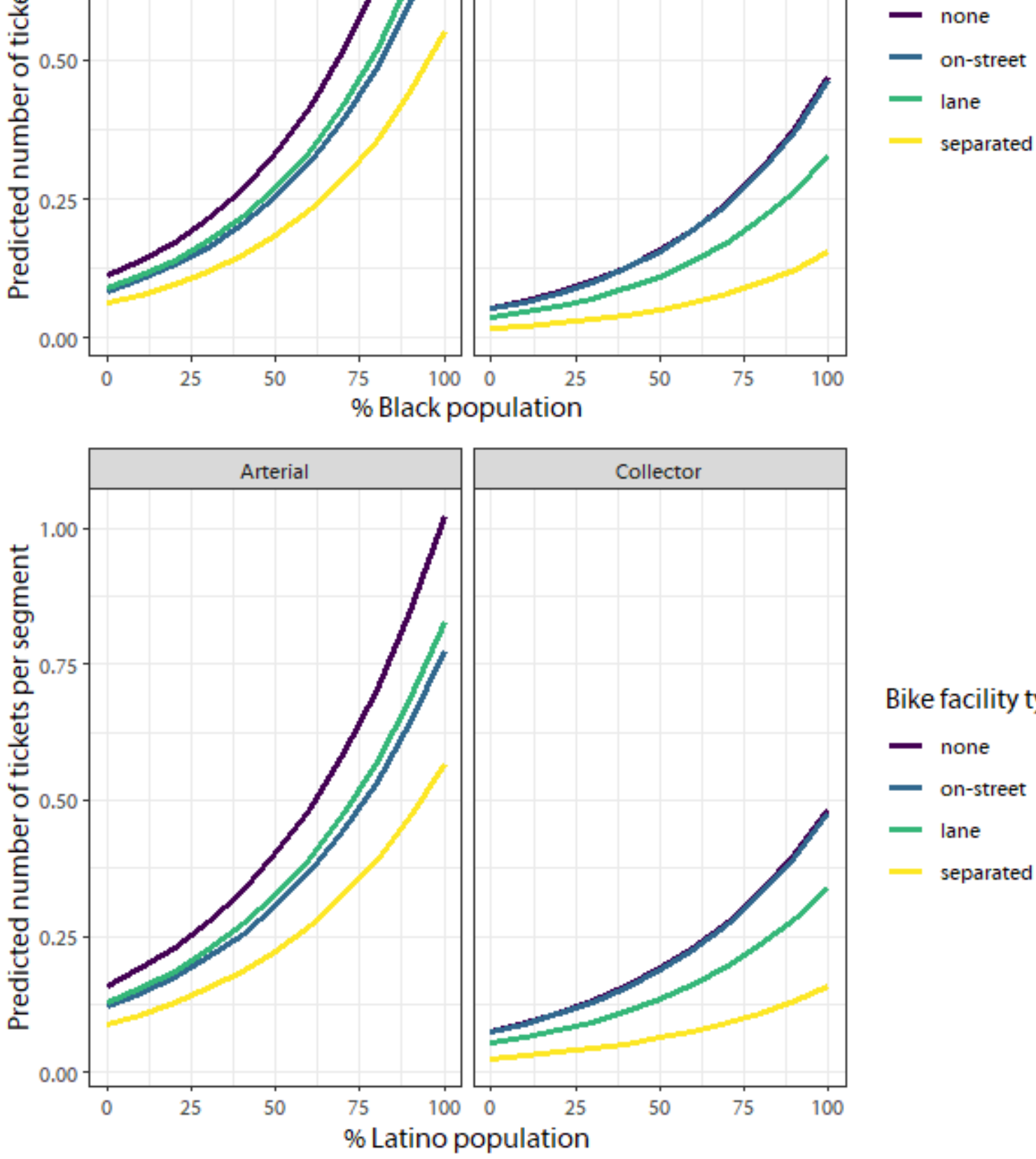

Bike facility type

- none

- on-street

- lane

- separated 
Figure 4: Effects of bicycle infrastructure on sidewalk riding citations by street functional classification

\subsection{Sensitivity analysis}

As described in Section 4.2, I tested different model specifications using three measures of cycling exposure; namely daily cycling volume per segment as recorded by Strava Metro, presented in the text, census tract bicycle commute share from the ACS, and the number of bicycle trips per census tract from the CMAP travel survey. Cycling volume was positively associated with the number of citations issued, an intuitive result in the relationship between number of cyclists and opportunities for police interaction. Neither commute share nor number of trips per census tract were statistically significant, indicating that area-wide measures may not be good proxies for cyclist exposure when examining street-level outcomes. Although not the focus of this study, the differences across the models illustrate the importance of selecting an accurate representation of cycling volume. Nevertheless, magnitude, direction, and statistical significance of model coefficients were consistent across the three models with a few exceptions for statistical significance among facility types.

The model was sensitive to the definition of bicycle facility type. In an earlier model specification, buffered bike lanes were included under the definition of separated bicycle facility. That categorization yielded counterintuitive model results in which the interaction term for separated facilities along arterial roads was not statistically significant $(p=0.14)$. A visual inspection using Google Street View revealed that some buffered lanes were buffered with paint only from the parking lane and not from the vehicle travel lanes. This suggests they might function more like non-buffered bicycle lanes. As Table 3 indicates, the re-specification yielded 
more intuitive results. While it would be preferable to specify bicycle facility type directly, there are too few of some individual types to adequately include in the model.

\section{Discussion and conclusion}

This study offers new evidence that transportation infrastructure is intertwined with unjust policing practices. The analysis of citations issued for riding bicycles on the sidewalk in Chicago supports other data that show majority Black and Latino neighborhoods were targets for policing, accounting for other factors. Bicycle infrastructure on high-traffic streets was associated with a lower incidence rate of enforcement actions, but that infrastructure was disproportionately absent from neighborhoods of color. Bicycle citations were not associated with safety needs in highercrash areas. Instead, underscoring statements from the Chicago Police Department itself, the analysis suggests that bicycle enforcement was instead tied to crime prevention strategies.

The results draw attention to the complicated relationship between planning, infrastructure, policing, and race. Planning cannot solely be held responsible for failure to provide bicycle infrastructure in communities of color. The development of transportation infrastructure involves a complex array of factors, including political decisions, funding availability, competing goals and priorities, and community needs and desires. As other scholars have documented, when cities have prioritized bicycle infrastructure, they have often done it explicitly for economic revitalization purposes, leading communities of color to be suspicious of and to reject their efforts Flanagan et al. (2016). Nevertheless, a bicycle plan is a city's most visible commitment to the provision of cycling infrastructure, and previous analyses of Chicago's bicycle plan and infrastructure have documented inequities in communities of color (Greenfield, 2015; Prelog, 2015). 
The conclusion that planning via policing or the assertion of police powers has been racist in intent or outcome is not new. Single family zoning, for example, effectively excluded people of color from white neighborhoods, and the development of many freeways and railways divided and destroyed Black and Brown communities. In Chicago specifically, research has traced how planning for redevelopment around the University of Chicago campus coincided with a geographic expansion of university police patrols whose purpose was to regulate belonging in a racially-mixed neighborhood surrounded by majority Black neighborhoods (Sherman, 2020). But various traffic safety approaches, including some implementations of Vision Zero, link together transportation planning and policing in explicit ways. Whereas previous strategies in which police enforcement was a central element of harm reduction-seat belt enforcement and drunk driving campaigns, for example — have largely not had a strong planning component, ${ }^{5}$ safe systems approaches call for data-driven identification of problem locations, traffic enforcement, and the planning and engineering of new and better infrastructure to work side-by-side. Careful examination of the unintended consequences of this synergy elucidates how planning has been complicit in the continuance of state violence against Black communities. It gives urgency to the need to repair harm in meaningful ways. Planners should thus be aware of these histories when advocating for what is on its face a reasonable strategy to reduce traffic violence. Scholars have argued that differences associated with marginalized identities should be made central to bicycle safety planning because not everyone experiences streets in the same ways (McCullough et al.,

${ }^{5}$ Jaywalking is arguably an exception (Norton, 2011). 
2019), though this is difficult to do because planners often do not have a full picture of who is cycling without specialized engagement and data collection (Golub et al., 2016).

While there is ample evidence for racial bias in the distribution of cycling tickets, it is also important to recognize the tickets were issued because cyclists were riding on sidewalks in the first place. Many sidewalk cycling tickets would not have been issued if the infrastructure associated with improved safety perceptions were available. In this light, bicycle infrastructure might be seen as a tool to advance racial justice, in that it helps provide cyclists in Black and Latino neighborhoods a small but important measure of protection from police overreach. This infrastructure is particularly important to keep cyclists safe when they feel the need to be seen on major streets, as described earlier. However, it is just as plausible that an infrastructure fix would shift cycling citations to other enforcement activities without sincere police reform. ${ }^{6}$ Regardless, planning and investment failures compound other inequities.

The evidence thus points to creating separated or on-street bike lanes as a safety intervention when travel routes take cyclists on busy streets. But those solutions must be created in close collaboration with community members. Cycling has been seen as a symbol of gentrification in low-income communities of color, including in Chicago (Lubitow et al., 2016; Rigolon and Németh, 2018), and advocates have become skeptical of bicycle infrastructure as a means to creating safer cycling conditions without community building and engagement. By some accounts, creating bicycle infrastructure in gentrifying neighborhoods could lead to

\footnotetext{
${ }^{6}$ See, for example, ACLU of Illinois (2019b), which alleges that increased accountability under stop and frisk reform led to a 71 percent increase in traffic stops, 85 percent of which involved Black or Latino motorists.
} 
increased enforcement and nuisance reporting against young people of color (Harris et al., 2020).

While this study does not allow for an examination of how gentrification differently impacts cyclists of color with respect to policing, evidence from other studies links increased order maintenance policing of people of color-a category of enforcement that sidewalk cycling citations might fall under - to the changing economic conditions in postindustrial cities (Laniyonu, 2018; Newberry, 2020; Sharp, 2014). While re-examining the role of enforcement in a holistic safety strategy is a necessary first step to improving cycling in all communities, it is not sufficient. Removing inequities in cycling infrastructure provision, while also ensuring communities are fully represented in bicycle planning processes, is crucial.

\section{Acknowledgments}

I am grateful to Kate Lowe and Olatunji Oboi Reed for their help reviewing and conceptualizing the research. Ashankh Jaishankhar and Shubhangi Rathor provided excellent research assistance. Thanks to the anonymous reviewers for their careful insights. This research did not receive any specific grant from funding agencies in the public, commercial, or not-for-profit sectors.

\section{References}

Abonour, R., 2018. Vision zero's enforcement problem: Using community engagement to craft equitable traffic safety strategies. UCLA Institute of Transportation Studies.

https://doi.org/10.17610/T6MS3Q

ACLU of Illinois, 2019a. Racism in the rear view mirror: Illinois traffic stop data 2015-2017.

ACLU of Illinois, 2019b. Chicago Police Traffic Stops Skyrocket, Disproportionately Impact Minority Drivers [WWW Document]. URL https://www.aclu-il.org/en/press-releases/chicagopolice-traffic-stops-skyrocket-disproportionately-impact-minority-drivers (accessed 10.21.2020).

Acs, G., Pendall, R., Treskon, M., Khare, A., 2017. The cost of segregation: National trends and the case of Chicago, 1990-2010. Urban Institute, Washington, DC. 
Aultman-Hall, L., Adams, M.F., 1998. Sidewalk Bicycling Safety Issues. Transportation Research Record 1636, 71-76. https://doi.org/10.3141/1636-11

Barajas, J.M., 2018. Not all crashes are created equal: Associations between the built environment and disparities in bicycle collisions. Journal of Transport and Land Use 11, 865882. https://doi.org/10.5198/jtlu.2018.1145

Baumgartner, F.R., Epp, D.A., Shoub, K., 2018. Suspect Citizens: What 20 Million Traffic Stops Tell Us about Policing and Race. Cambridge University Press.

Bhatia, D., Richmond, S.A., Loo, C.K.J., Rothman, L., Macarthur, C., Howard, A., 2016. Examining the Impact of Cycle Lanes on Cyclist-Motor Vehicle Collisions in the City of Toronto. Journal of Transport \& Health 3, 523-528. https://doi.org/10.1016/j.jth.2016.04.002

Braun, L.M., Rodriguez, D.A., Gordon-Larsen, P., 2019. Social (in)equity in access to cycling infrastructure: Cross-sectional associations between bike lanes and area-level sociodemographic characteristics in 22 large U.S. cities. Journal of Transport Geography 80, 102544.

https://doi.org/10.1016/j.jtrangeo.2019.102544

Brooks, M.E., Kristensen, K., Benthem, K.J. van, Magnusson, A., Berg, C.W., Nielsen, A., Skaug, H.J., Mächler, M., Bolker, B.M., 2017. glmmTMB Balances Speed and Flexibility Among Packages for Zero-inflated Generalized Linear Mixed Modeling. The R Journal 9, 378400 .

Brown, C., Harvey, E., Sinclair, J., 2016. Understanding barriers to bicycle access \& use in Black and Hispanic communities in New Jersey. Alan M. Voorhees Transportation Center, Rutgers.

Buehler, R., Dill, J., 2016. Bikeway Networks: A Review of Effects on Cycling. Transport Reviews 36, 9-27. https://doi.org/10.1080/01441647.2015.1069908

Caros, N.S., Chow, J.Y.J., 2020. Effects of violent crime and vehicular crashes on active mode choice decisions in New York City. Travel Behaviour and Society 18, 37-45.

https://doi.org/10.1016/j.tbs.2019.09.004

Chaloux, N., El-Geneidy, A., 2019. Rules of the Road: Compliance and Defiance among the Different Types of Cyclists. Transportation Research Record 2673, 34-43.

https://doi.org/10.1177/0361198119844965

Chicago Department of Transportation, 2012. Chicago Streets for Cycling 2020.

City of Chicago, 2017. Vision Zero Chicago Action Plan 2017-2019.

City of Los Angeles, 2015. Vision Zero Los Angeles: 2015-2025. Los Angeles.

Conner, M., 2017. Traffic Justice: Achieving Effective and Equitable Traffic Enforcement in the Age of Vision Zero Colloquium: Getting There from Here: An Exploration of Regionalism and Transportation in the United States. Fordham Urb. L.J. 44, 969-1004. 
Coren, C., Lowe, K., 2020. Mobility in and Beyond Communities: A Qualitative Study of Mobility Justice Issues on the South and Southwest Sides of Chicago. University of Illinois at Chicago.

Cradock, A.L., Troped, P.J., Fields, B., Melly, S.J., Simms, S.V., Gimmler, F., Fowler, M., 2009. Factors Associated with Federal Transportation Funding for Local Pedestrian and Bicycle Programming and Facilities. J Public Health Pol 30, S38-S72.

https://doi.org/10.1057/jphp.2008.60

Cuba, J., 2020. NYPD Targets Black and Brown Cyclists For Biking On The Sidewalk [WWW Document]. URL https://nyc.streetsblog.org/2020/06/22/nypd-targets-black-and-brown-cyclistsfor-biking-on-the-sidewalk/ (accessed 9.14.2020).

Dadashova, B., Griffin, G.P., Das, S., Turner, S., Sherman, B., 2020. Estimation of Average Annual Daily Bicycle Counts using Crowdsourced Strava Data. Transportation Research Record 0361198120946016. https://doi.org/10.1177/0361198120946016

DiGioia, J., Watkins, K.E., Xu, Y., Rodgers, M., Guensler, R., 2017. Safety impacts of bicycle infrastructure: A critical review. Journal of Safety Research 61, 105-119.

https://doi.org/10.1016/j.jsr.2017.02.015

Dumbaugh, E., Saha, D., Merlin, L., 2020. Toward Safe Systems: Traffic Safety, Cognition, and the Built Environment. Journal of Planning Education and Research 0739456X20931915. https://doi.org/10.1177/0739456X20931915

Eitle, D., D’Alessio, S.J., Stolzenberg, L., 2002. Racial Threat and Social Control: A Test of The Political, Economic, and Threat of Black Crime Hypotheses. Social Forces 81, 557-576.

https://doi.org/10.1353/sof.2003.0007

Elvik, R., Bjørnskau, T., 2017. Safety-in-numbers: A systematic review and meta-analysis of evidence. Safety Science 92, 274-282. https://doi.org/10.1016/j.ssci.2015.07.017

Federal Highway Administration, 2017. National Household Travel Survey.

Flanagan, E., Lachapelle, U., El-Geneidy, A., 2016. Riding tandem: Does cycling infrastructure investment mirror gentrification and privilege in portland, OR and chicago, IL? Research in Transportation Economics, Transportation and land development: A global view 60, 14-24. https://doi.org/10.1016/j.retrec.2016.07.027

Fleisher, A., Wier, M.L., Hunter, M., 2016. A vision for transportation safety: Framework for identifying best practice strategies to advance Vision Zero. Transportation Research Record: Journal of the Transportation Research Board 2582, 72-86. https://doi.org/10.3141/2582-09

Fliss, M.D., Baumgartner, F.R., Delamater, P., Marshall, S., Poole, C., Robinson, W., 2020. Reprioritizing traffic stops to reduce motor vehicle crash outcomes and racial disparities. Injury Epidemiology 7, 3. https://doi.org/10.1186/s40621-019-0227-6 
Gelman, A., Hill, J., 2007. Data analysis using regression and multilevel/hierarchical models, Analytical methods for social research. Cambridge University Press, Cambridge ; New York.

Golub, A., Hoffman, M.L., Lugo, A.E., Sandoval, G.F. (Eds.), 2016. Bicycle Justice and Urban Transformation: Biking for All?, Routledge equity, justice and the sustainable city. Routledge, New York, NY.

Greenfield, J., 2018. CPD Doubles Down on Claim That Heavy Bike Enforcement Is a Fair AntiViolence Strategy [WWW Document]. URL https:/chi.streetsblog.org/2018/08/14/cpd-doublesdown-on-claim-that-bike-enforcement-is-a-fair-anti-violence-strategy/ (accessed 6.15.2020).

Greenfield, J., 2015. Chicago's bike plan is inequitable, says report based on wrong map.

Harris, B., Rigolon, A., Fernandez, M., 2020. "To them, we're just kids from the hood": Citizenbased policing of youth of color, "white space," and environmental gentrification. Cities 107, 102885. https://doi.org/10.1016/j.cities.2020.102885

Hoffmann, M.L., 2016. Bike Lanes are White Lanes: Bicycle Advocacy and Urban Planning. University of Nebraska Press, Lincoln.

Howell, K.B., 2016. The Costs of Broken Windows Policing: Twenty Years and Counting. Cardozo L. Rev. 37, 1059-1073.

Illinois, A. of, 2015. Stop and Frisk in Chicago.

Illinois Attorney General, 2019. Chicago Police Department Consent Decree Fact Sheet.

Ingram, J.R., 2007. The Effect of Neighborhood Characteristics on Traffic Citation Practices of the Police. Police Quarterly 10, 371-393. https://doi.org/10.1177/1098611107306995

Investigatory Stop and Protective Pat Down Settlement Agreement, 2015.

Jacobsen, P.L., 2003. Safety in Numbers: More Walkers and Bicyclists, Safer Walking and Bicycling. Inj Prev 9, 205-209. https://doi.org/10.1136/ip.9.3.205

Kang, L., Fricker, J.D., 2013. Bicyclist commuters' choice of on-street versus off-street route segments. Transportation 40, 887-902. https://doi.org/10.1007/s11116-013-9453-x

Kaufman, E., 2016. Policing mobilities through bio-spatial profiling in New York City. Political Geography 55, 72-81. https://doi.org/10.1016/j.polgeo.2016.07.006

Laniyonu, A., 2018. Coffee Shops and Street Stops: Policing Practices in Gentrifying Neighborhoods. Urban Affairs Review 54, 898-930. https://doi.org/10.1177/1078087416689728

League of American Bicyclists, 2020. Bicycling and Walking in the United States: 2018 Benchmarking Report.

Lee, K., Sener, I.N., 2020. Strava Metro data for bicycle monitoring: A literature review. Transport Reviews 0, 1-21. https://doi.org/10.1080/01441647.2020.1798558 
Levine, H., Siegel, L., 2014. Criminal court summonses in New York City.

Lieberman, D., Dansky, K., 2016. The Degradation of Civil Society and Hyper-Aggressive Policing in Communities of Color in New York City Symposium: The Underbelly of the Beast: Misdemeanor Practice in the Era of Broken Windows and Saturation Policing. Cardozo L. Rev. 37, 955-972.

Lubitow, A., Miller, T.R., 2013. Contesting sustainability: Bikes, race, and politics in portlandia. Environmental Justice 6, 121-126. https://doi.org/10.1089/env.2013.0018

Lubitow, A., Zinschlag, B., Rochester, N., 2016. Plans for Pavement or for People? The Politics of Bike Lanes on the 'Paseo Boricua' in Chicago, Illinois. Urban Stud 53, 2637-2653. https://doi.org/10.1177/0042098015592823

Lusk, A.C., Willett, W.C., Morris, V., Byner, C., Li, Y., 2019. Bicycle Facilities Safest from Crime and Crashes: Perceptions of Residents Familiar with Higher Crime/Lower Income Neighborhoods in Boston. International Journal of Environmental Research and Public Health 16, 484. https://doi.org/10.3390/ijerph16030484

Marshall, W.E., Piatkowski, D., Johnson, A., 2017. Scofflaw bicycling: Illegal but rational. Journal of Transport and Land Use 10. https://doi.org/10.5198/jtlu.2017.871

McCullough, S.R., Lugo, A., Stokkum, R. van, 2019. Making Bicycling Equitable: Lessons from Sociocultural Research. https://doi.org/10.7922/G22R3PWK

Mitchell, O., Ridgeway, G., 2018. Assessing the Fairness and Effectiveness of Bicycle Stops in Tampa. Police Quarterly 21, 461-485. https://doi.org/10.1177/1098611118781344

Monsere, C.M., McNeil, N., Dill, J., 2012. Multiuser Perspectives on Separated, On-Street Bicycle Infrastructure. Transportation Research Record 2314, 22-30.

https://doi.org/10.3141/2314-04

National Highway Traffic Safety Administration, 2021. Update to Special Reports on Traffic Safety During the COVID-19 Public Health Emergency: Fourth Quarter Data (No. DOT HS 813 135), Traffic Safety Facts. U.S. Department of Transportation, Washington, D.C.

National Highway Traffic Safety Administration, 2019. Fatality Analysis Reporting System (FARS).

Nelson, T., Ferster, C., Laberee, K., Fuller, D., Winters, M., 2020. Crowdsourced data for bicycling research and practice. Transport Reviews $0,1-18$.

https://doi.org/10.1080/01441647.2020.1806943

New York City Police Department, 2015. Broken Windows and quality of life policing in New York City.

Newberry, J.L., 2020. Policing Strategies and Potential Targets: The Influence of Gentrification and Crime on the Stoppage of Blacks and Hispanics in New York City. Papers in Applied Geography 1-16. https://doi.org/10.1080/23754931.2020.1814848 
Norton, P.D., 2011. Fighting traffic: The dawn of the motor age in the American city, Inside technology. MIT Press, Cambridge, Mass. London.

Novak, K.J., Chamlin, M.B., 2012. Racial Threat, Suspicion, and Police Behavior: The Impact of Race and Place in Traffic Enforcement. Crime \& Delinquency 58, 275-300.

https://doi.org/10.1177/0011128708322943

Pierson, E., Simoiu, C., Overgoor, J., Corbett-Davies, S., Jenson, D., Shoemaker, A., Ramachandran, V., Barghouty, P., Phillips, C., Shroff, R., Goel, S., 2020. A large-scale analysis of racial disparities in police stops across the United States. Nature Human Behaviour 4, 736745. https://doi.org/10.1038/s41562-020-0858-1

Prelog, R., 2015. Equity of Access to Bicycle Infrastructure. League of American Bicyclists, Washington, DC.

Pucher, J., Dill, J., Handy, S., 2010. Infrastructure, Programs, and Policies to Increase Bicycling: An International Review. Preventive Medicine 50, S106-S125.

https://doi.org/10.1016/j.ypmed.2009.07.028

Ralph, L., 2020. The torture letters: Reckoning with police violence. University of Chicago Press, Chicago.

Reynolds, C.C., Harris, M.A., Teschke, K., Cripton, P.A., Winters, M., 2009. The Impact of Transportation Infrastructure on Bicycling Injuries and Crashes: A Review of the Literature. Environ Health 8, 47. https://doi.org/10.1186/1476-069X-8-47

Rigolon, A., Németh, J., 2018. "We're not in the business of housing:" Environmental gentrification and the nonprofitization of green infrastructure projects. Cities $81,71-80$. https://doi.org/10.1016/j.cities.2018.03.016

Rojek, J., Rosenfeld, R., Decker, S., 2012. Policing Race: The Racial Stratification of Searches in Police Traffic Stops. Criminology 50, 993-1024. https://doi.org/10.1111/j.1745-

9125.2012.00285.x

Schneider, R.J., Kusch, J., Dressel, A., Bernstein, R., 2018. Can a twelve-week intervention reduce barriers to bicycling among overweight adults in low-income Latino and Black communities? Transportation Research Part F: Traffic Psychology and Behaviour 56, 99-112. https://doi.org/10.1016/j.trf.2018.03.023

Shahum, L., 2020. Acting for Racial Justice \& Just Mobility [WWW Document]. URL https://visionzeronetwork.org/acting-for-racial-justice-just-mobility/ (accessed 6.15.2020).

Sharp, E.B., 2014. Politics, Economics, and Urban Policing: The Postindustrial City Thesis and Rival Explanations of Heightened Order Maintenance Policing. Urban Affairs Review 50, 340 365. https://doi.org/10.1177/1078087413490397 
Sherman, S.A., 2020. From Revanchism to Inclusion: Institutional Forms of Planning and Police in Hyde Park, Chicago. Journal of Planning Education and Research 40, 139-150.

https://doi.org/10.1177/0739456X19877683

State of Illinois, 2020. Torture Inquiry and Relief Commission [WWW Document]. URL https://www2.illinois.gov:443/sites/tirc/Pages/default.aspx (accessed 9.14.2020).

Taylor, D.B., 2020. George Floyd Protests: A Timeline. The New York Times: U.S.

Teschke, K., Harris, M.A., Reynolds, C.C., Winters, M., Babul, S., Chipman, M., Cusimano, M.D., Brubacher, J.R., Hunte, G., Friedman, S.M., Monro, M., Shen, H., Vernich, L., Cripton, P.A., 2012. Route Infrastructure and the Risk of Injuries to Bicyclists: A Case-Crossover Study. Am J Public Health 102, 2336-2343. https://doi.org/10.2105/AJPH.2012.300762

U. S. Census Bureau, 2020. American Community Survey 5-Year Estimates: 2014-2018.

Untokening Collective, 2017. Untokening 1.0 — Principles of Mobility Justice.

Vision Zero SF, 2019. Vision Zero action strategy: Eliminating traffic deaths in San Francisco. San Francisco, CA.

Warren, P., Tomaskovic-Devey, D., Smith, W., Zingraff, M., Mason, M., 2006. Driving While Black: Bias Processes and Racial Disparity in Police Stops. Criminology 44, 709-738.

https://doi.org/10.1111/j.1745-9125.2006.00061.x

Winters, M., Babul, S., Becker, H.J.E.H., Brubacher, J.R., Chipman, M., Cripton, P., Cusimano, M.D., Friedman, S.M., Harris, M.A., Hunte, G., Monro, M., Reynolds, C.C.O., Shen, H., Teschke, K., 2012. Safe Cycling: How Do Risk Perceptions Compare With Observed Risk? Can J Public Health 103, S42-S47. https://doi.org/10.1007/BF03403834

Wisniewski, M., 2019. Bike tickets drop citywide — but most are still issued in majority black areas. Chicago Tribune: Transportation, Business, News, Breaking News.

Wisniewski, M., 2018. Black neighborhoods still see most bike tickets, police data show. Chicago Tribune: Column.

Wisniewski, M., 2017. 'Biking while black': Chicago minority areas see the most bike tickets. Chicago Tribune. 